\title{
Treatment outcomes of congenital pseudarthrosis of the tibia at Beit Cure International Hospital in Blantyre, Malawi
}

\author{
Inyas L. Akaro ${ }^{1,2}$, Kyle James³ ${ }^{3}$ Linda Chokotho 3 , David Burgess ${ }^{3}$, Nyengo Mkandawire ${ }^{4}$, Pamela T.K. Samoyo ${ }^{5}$ \\ 1. Department of Orthopaedics and Traumatology, Bugando Medical Centre, Mwanza, Tanzania \\ 2. Department of Orthopaedics and Traumatology, Catholic University of Health and Allied Sciences, Mwanza, Tanzania \\ 3. Beit Cure International Hospital, Blantyre, Malawi \\ 4. Department of Surgery, College of Medicine, University of Malawi, Blantyre, Malawi \\ 5. Department of Surgery, Kilimanjaro Christian Medical University College, Moshi, Tanzania \\ Correspondence: Dr Inyas L. Akaro (mmeku81@gmail.com)
}

๑) 2018 I.L. Akaro et al. This open access article is licensed under a Creative Commons Attribution 4.0 International License (http://creativecommons.org/licenses/by/4.0/), which permits unrestricted use, distribution, and reproduction in any medium, provided you give appropriate credit to the original author(s) and the source, provide a link to the Creative Commons license, and indicate if changes were made.

East Cent Afr J Surg. 2018 Dec;23(3):109-118 https://dx.doi.org/10.4314/ecajs.v23i3.5

\begin{abstract}
Background

Congenital pseudarthrosis of the tibia (CPT) is a rare condition. The natural history of CPT includes persistent instability and progressive deformity. Several CPT treatment methods have been practiced, however, in Africa where there is scarce information on the modalities of treatment available and their outcomes.
\end{abstract}

\section{Methods}

A retrospective cross-sectional study which was conducted among patients with CPT at Beit Cure International Hospital (BCIH), Malawi. Forty-four patients were recruited in this study and their treatment modalities and outcomes were analyzed.

\section{Results}

Out of 44 patients recruited in this study, majority (63.6\%) were male. The majority of cases were stage 4 congenital tibia pseudarthrosis by Crawford classification. Most patients were treated by more than one surgical modality; however, surgical excision and intramedullary rodding was commonly used (54.7\%). The outcomes of treatment were good in 5\%, fair in 30\%, with amputation in $45 \%$ and poor outcomes in $20 \%$ of the patients. Complications developed in $60 \%$ of patients, predominated by limb length discrepancy. The foot and ankle status were rated by Oxford Foot and Ankle scoring system (OxFAQ).

\section{Conclusions}

Congenital pseudarthrosis of the tibia is a complex congenital disorder with multiple modalities of treatment. Majority of the patients were treated by more than one operation. Some patients ended up with amputation or poor outcome. Limb length discrepancy, deep infection and pin tract infection are among the common complications.

Keywords: congenital pseudarthrosis, tibia, treatment outcomes, Malawi

\section{Introduction}

Congenital pseudarthrosis of the tibia (CPT) is rare, with reported incidence of 1 per 190,000 live births ${ }^{1}$ and 1:53,000 in another study. ${ }^{2}$ Congenital pseudarthrosis of the tibia is one of the most difficult conditions to treat. It has a natural history of persistent instability, progressive deformity ${ }^{3}$ and is strongly associated with neurofibromatosis. ${ }^{4}$

Several treatment options have been applied in treating $\mathrm{CPT}$, including vascularized fibular grafting, circular external fixation (Ilizarov or Taylor Spatial frames), intramedul- lary rodding and the use of biological compounds like hyalonect.

The CPT treatment requires several revision operations to achieve the union of the tibia and fibula with less or no deformity.

The treatment of the CPT is associated with several complications including limb length discrepancy, refractures, ankle valgus and pin tract infection. Amputation is done for a few cases when further reconstruction has failed.

In Malawi, the majority of patients with $\mathrm{CPT}$ are treat- 
Table 1: Social and demographic characteristics of participants $(N=44)$

\begin{tabular}{|c|c|c|c|c|c|c|}
\hline Patient number & Sex & Side & Age (years) & Age at first visit (years) & Length of follow up (years) & Crawford classification \\
\hline 1 & Male & Right & 19 & 8 & 11 & Unknown \\
\hline 2 & Female & Right & 11 & 4 & 7 & 4 \\
\hline 3 & Male & Left & 15 & 10 & 5 & 2 \\
\hline 4 & Male & Left & 6 & 2 & 4 & 2 \\
\hline 5 & Female & Bilateral & 27 & 16 & 11 & Unknown \\
\hline 6 & Male & Left & 22 & 11 & 11 & 4 \\
\hline 7 & Male & Right & 14 & 3 & 11 & Unknown \\
\hline 8 & Male & Left & 16 & 5 & 11 & Unknown \\
\hline 9 & Female & Left & 26 & 16 & 10 & 4 \\
\hline 10 & Male & Left & 11 & 2 & 9 & 4 \\
\hline 11 & Male & Left & 20 & 12 & 8 & Unknown \\
\hline 12 & Male & Left & 12 & 5 & 7 & Unknown \\
\hline 13 & Female & Left & 13 & 1 & 12 & 4 \\
\hline 14 & Male & Left & 22 & 16 & 6 & Unknown \\
\hline 15 & Male & Left & 17 & 11 & 6 & Unknown \\
\hline 16 & Female & Right & 10 & 9 & 1 & 2 \\
\hline 17 & Male & Left & 23 & 11 & 12 & Unknown \\
\hline 18 & Male & Left & 13 & 3 & 10 & 4 \\
\hline 19 & Male & Left & 12 & 6 & 6 & Unknown \\
\hline 20 & Male & Right & 12 & 2 & 10 & Unknown \\
\hline 21 & Female & Right & 11 & 8 & 3 & Unknown \\
\hline 22 & Male & Right & 17 & 11 & 6 & Unknown \\
\hline 23 & Female & Right & 6 & 4 & 2 & Unknown \\
\hline 24 & Male & Left & 4 & 3 & 1 & 4 \\
\hline 25 & Female & Left & 19 & 9 & 10 & 2 \\
\hline 26 & Male & Left & 16 & 15 & 1 & 4 \\
\hline 27 & Male & Right & 13 & 10 & 3 & 4 \\
\hline 28 & Male & Right & 14 & 4 & 10 & Unknown \\
\hline 29 & Female & Left & 26 & 15 & 11 & Unknown \\
\hline 30 & Male & Left & 12 & 1 & 11 & Unknown \\
\hline 31 & Male & Left & 20 & 8 & 12 & 4 \\
\hline 32 & Male & Left & 10 & 7 & 3 & Unknown \\
\hline 33 & Female & Right & 5 & 2 & 3 & 4 \\
\hline 34 & Female & Right & 10 & 6 & 4 & 4 \\
\hline 35 & Male & Right & 14 & 4 & 10 & 4 \\
\hline 36 & Male & Right & 10 & 4 & 6 & 4 \\
\hline 37 & Female & Right & 7 & 5 & 2 & 4 \\
\hline 38 & Female & Right & 5 & 2 & 3 & 4 \\
\hline 39 & Male & Right & 15 & 11 & 4 & 2 \\
\hline 40 & Female & Left & 12 & 7 & 5 & 2 \\
\hline 41 & Male & Left & 24 & 13 & 11 & 2 \\
\hline 42 & Male & Right & 22 & 11 & 11 & 4 \\
\hline 43 & Female & Left & 17 & 9 & 8 & Unknown \\
\hline 44 & Female & Right & 27 & 14 & 13 & Unknown \\
\hline
\end{tabular}


ed at Beit Cure International Hospital (BCIH), as this is the only specialized paediatric orthopaedic hospital in the country. Several treatment methods have been used at BCIH including pseudarthrosis excision, bone grafting and casting, intramedullary rush rodding, circular external fixation and/ or amputation.

The evaluation of treatment outcomes on management of CPT has been done largely in developed countries, with scarcity of information in middle- and low-income countries.

This study aimed at evaluation of treatment outcomes among patients with congenital pseudarthrosis of the tibia in Malawi to help guardians' counseling and clinician decision making. Also, this will add to evidence-based information on effective utilization of resources available in middle- and low- income countries for the management of CPT.

\section{Methods}

A retrospective cross-sectional study was conducted at Beit Cure International Hospital, Malawi. Ethical approval was obtained from the University of Malawi, College of Medicine Research and Ethics Committee (COMREC). The permission to conduct the study was obtained from Beit Cure International Hospital, Malawi. Consent from patients/guardians and assent was obtained and confidentiality maintained.

This study recruited all children who had CPT treatment at Beit Cure International Hospital in the years from 20032014. The case notes and contact details of patients were extracted from the hospital database. A total of 44 children fit inclusion criteria and their clinical and radiological data were assessed. Out of the 44 patients, 20 children were successfully followed-up until the end of the study.

In this study, evaluation of treatment outcomes was grouped into three categories as described by Morris in USA into: 1) good results; a solid tibial union which uses no external support or splint, is fully active with no pain and not troubled by the $\operatorname{leg}^{3}$; 2) fair results; a tibial union with minimal use of external support or splint, a deformity though noticeable is neither severe nor incapacitating and patient's daily activities are not affected ${ }^{3}$; 3) poor results; a non-union or tenuous union requiring external support, severe functional and cosmetic handicap which was judged that amputation would have been preferable. ${ }^{3}$

Functional assessment of the patients has been done using the Oxford Ankle and Foot Questionnaire (OxFAQ). This has been found useful in evaluating various disease conditions that affect the foot and/or ankle. ${ }^{5,6}$

Their current leg status, complications and OxFAQ scores were assessed, including the accessibility of prosthesis to amputees.

\section{Results}

Nearly two-thirds (28 of $44,63.6 \%$ ) of participants were male. $24 / 44(54.5 \%)$ of participants were affected on the left side. The mean age at the initial hospital visit was 8.7 years (CI 6.2-11.1 years). Participants' age range was 4-27 years (mean 14.7 years with a 95\% CI of 12.7-16.7 years).

Table 2: Number of operations performed on followed-up patients with their outcomes and complications $(\mathbf{N}=\mathbf{2 0})$

\begin{tabular}{|c|c|c|c|c|c|}
\hline Number of Surgeries & Frequency (\%) & Outcomes & P-value & Complications & P-value \\
\hline 1 & $5(25 \%)$ & $\begin{array}{l}\text { 2-Fair } \\
\text { 3-Amputation }\end{array}$ & \multirow{7}{*}{0.0893} & \begin{tabular}{|l|} 
No \\
1 -LLD \\
\end{tabular} & \multirow{7}{*}{0.0591} \\
\hline 2 & $5(25 \%)$ & $\begin{array}{l}\text { 2-Fair } \\
\text { 1-Poor } \\
\text { 2-Amputation }\end{array}$ & & 3-LLD & \\
\hline 3 & $6(30 \%)$ & $\begin{array}{l}\text { 2-Fair } \\
\text { 4-Amputation }\end{array}$ & & $\begin{array}{l}\text { 2-Deep } \\
\text { infection } \\
\text { 1-LLD }\end{array}$ & \\
\hline 4 & $1(5 \%)$ & 1-Poor & & $\begin{array}{l}\text { 1-Deep } \\
\text { infection } \\
1-L L D\end{array}$ & \\
\hline 5 & $1(5 \%)$ & 1-Good & & 1-LLD & \\
\hline 7 & $1(5 \%)$ & 1-Poor & & $\begin{array}{l}\text { 1-Pin tract } \\
\text { infection } \\
\text { 1-LLD }\end{array}$ & \\
\hline 8 & $1(5 \%)$ & 1-Poor & & $\begin{array}{l}\text { 1-Deep } \\
\text { infection } \\
1 \text {-LLD }\end{array}$ & \\
\hline
\end{tabular}

LLD-Limb length discrepancy* 
Table 3: Type of surgical operations performed on participants

\begin{tabular}{|c|c|c|c|c|c|}
\hline Type of surgical operation/s & Frequency $(\%)$ & Outcome & P-value & Complications & P-value \\
\hline Surgical excision and casting & $2(3.1 \%)$ & 1-Amputation & \multirow{5}{*}{0.4493} & & \multirow{5}{*}{0.2748} \\
\hline $\begin{array}{l}\text { Surgical excision and intramedullary } \\
\text { rodding }\end{array}$ & $35(54.7 \%)$ & $\begin{array}{l}\text { 1-Good } \\
\text { 6-Fair } \\
\text { 2-Poor } \\
\text { 3-Amputation }\end{array}$ & & $\begin{array}{l}\text { 1-Pin tract } \\
\text { infection } \\
\text { 4-Deep } \\
\text { infection }\end{array}$ & \\
\hline $\begin{array}{l}\text { Surgical excision and circular external } \\
\text { fixation }\end{array}$ & $12(18.8 \%)$ & $\begin{array}{l}\text { 2-Poor } \\
\text { 1-Amputation }\end{array}$ & & $\begin{array}{l}\text { 1-Deep } \\
\text { infection } \\
\text { 1-Pin tract } \\
\text { infection }\end{array}$ & \\
\hline Amputation & $9(14.1 \%)$ & 4 -Amputation & & & \\
\hline Others (osteosynthesis, bone cement) & $6(9.3 \%)$ & Unknown & & $\begin{array}{l}\text { 1-Deep } \\
\text { infection }\end{array}$ & \\
\hline
\end{tabular}

Follow-up mean duration was 7.3 years (ranging from 1-13 years). Participants for whom initial X-rays were accessible (24 of the 44 ) had tibia pseudarthrosis Crawford stage 4 (70.8\%).

These patients had 3, 2 or 1 surgery/ies performed; however, one patient had 8 surgeries done. The number of surgeries performed was not statistically significant to treatment outcomes (P-value 0.0893) and/or treatment complications (P-value 0.0591).

The most common procedure to be performed was surgical excision and intramedullary rodding (54.7\%). The type of surgical operation done was not statistically significant to treatment outcomes (P-value 0.4493 ) and/or treatment complications (P-value 0.2748).

There was no association between pseudarthrosis stage according to Crawford classification and treatment outcomes (P-value 0.6461), also, treatment complications (P-value 0.3086). However, the age at initial treatment was significantly associated with treatment outcomes (P-value 0.000 ) but not treatment complications (P-value 0.3576).

Treatment outcomes in this study were reflected by leg status, complications and Oxford Foot and Ankle Questionnaire scores. Leg status had amputation in 9/20 patients, poor in $4 / 20$ patients, fair in $6 / 20$ patients and good in $1 / 20$ patients. Complications developed in $12 / 20$ patients, the majority being limb length discrepancy ranging from $1-11 \mathrm{~cm}$ (mean $6.6 \mathrm{~cm}$ ). Foot and ankle status assessment was done for participants who were not amputated. Children OxFAQ averages were; physical score 14.5, school score 9.6, emotional score 10.2 and shoe wearing score 2.7 with a total children score of 37.4. Parent OxFAQ averages were; physical score 10.6, school score 6.8, emotional score 8.1 , shoe wearing score 1.8 and a total parent score of 28.5 .

\section{Discussion}

\section{Social and demographic characteristics of participants}

In this study, congenital pseudarthrosis of the tibia affected mainly males $(63.6 \%)$. The majority of patients $(70.8 \%)$ by Crawford classification ${ }^{7}$ were pseudarthrosis stage 4 , followed by stage 2 and no patients were found in stage 1 or 3 . Stage 4 is the most difficult stage to manage. These findings are inconsistent with a study which was done by Horn et al in Norway where $9 / 17$ (52.9\%) were stage 4 followed by stage 3 according to Crawford classification. ${ }^{2}$ Findings in Malawi could be due to the tradition of seeking health care late when the condition is worse or painful secondary to fracture. However, there is a limitation that some patients' initial pre-treatment X-rays were not available to determine their Crawford stage.

\section{Treatment methods}

All patients in this study were treated surgically. Most patients had three, two or one surgery/ies, accounted for by $30 \%, 25 \%$ and $25 \%$ respectively. However, one patient had 8 surgeries done where the multiple procedures were due to refracturing at the time that the bone was still fixed by implant or after removal of a fixator or rod. This high number of operations was also found in a research done in Norway and elsewhere. ${ }^{2,8}$ Number of operations performed was not statistically associated with either treatment outcomes or complications. Those patients who had more than 3 operations ended up with poor results (2/4), fair results (1/4) and good results $(1 / 4)$.

Despite the fact that about $75 \%$ of all patients in this study had more than one operation, majority were treated by surgical excision and intramedullary rodding (54.7\%). The next most common method of treatment was surgical excision and circular external fixation using Ilizarov frames $(18.8 \%)$, followed by amputation. Bone grafting was done in $27 / 32$ patients $(84.4 \%)$. These modalities of treatment have been instituted for treating CPT in different settings. ${ }^{9,10}$

\section{Treatment outcomes}

In this study there was no significant statistical associ- 
Table 4: Treatment modalities with outcomes for patients followed-up until the end of the study $(\mathrm{N}=\mathbf{2 0})$

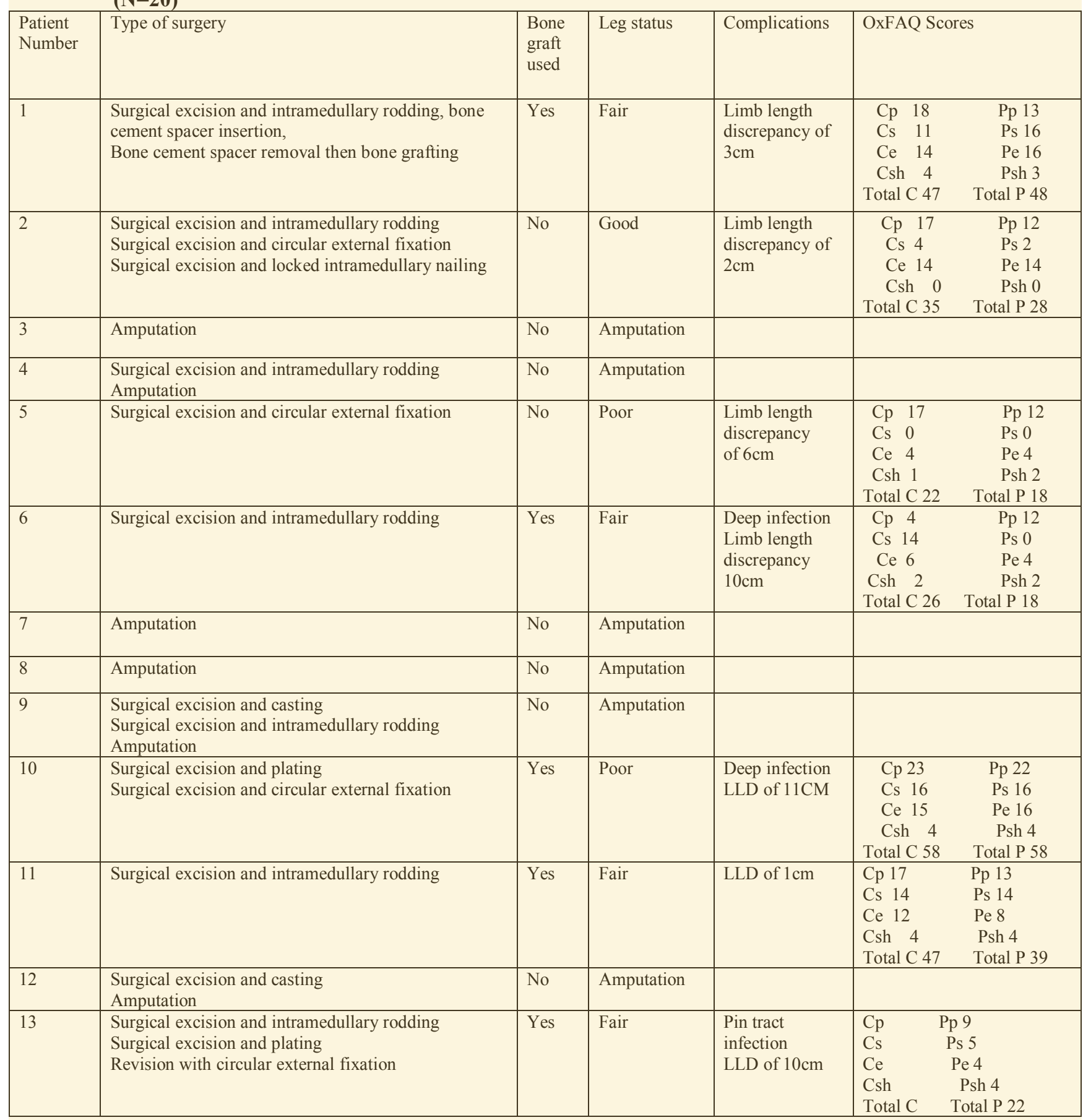

\section{Key: C-Children, P-Parents, p-physical score, s-school score, e-emotional score and sh-shoe wearing} score, LLD -Limb length discrepancy

ation between pseudarthrosis stage according to Crawford classification before initial operation and treatment outcomes. This was similar to a study which was done in Texas ${ }^{10}$ and reflects on the biological nature of the problem and not merely mechanical.

The age at which initial treatment was done is associated with treatment outcomes. This was different from another study which showed no significant association between the age at initial treatment and treatment outcomes. ${ }^{10}$ In this current study for instance, most poor results (3/4) were seen in patients whose age at initial treatment was less than 3 years old.

The outcomes of treatment in this study were as follows: good results in $1 / 20(5 \%)$, fair results $6 / 20(30 \%)$, poor results 4/20 (20\%), and amputation 9/20 (45\%). These findings are consistent with another study which showed: good results in $9 / 40$ patients $(22.5 \%)$, fair results in $9 / 40$ patients (22.5\%) poor results in $8 / 40$ patients $(20 \%)$ and amputation in $14 / 40$ patients $(35 \%){ }^{3}$ The higher rate of amputation and poor outcomes reflects the difficulties of treating CPT even 
Table 4 continued

\begin{tabular}{|c|c|c|c|c|c|c|}
\hline $\begin{array}{l}\text { Patient } \\
\text { Number }\end{array}$ & Type of surgery & $\begin{array}{l}\text { Bone } \\
\text { graft } \\
\text { used }\end{array}$ & Leg status & Complications & \multicolumn{2}{|c|}{ OxFAQ Scores } \\
\hline 14 & $\begin{array}{l}\text { Surgical excision and intramedullary rodding } \\
\text { Amputation }\end{array}$ & Yes & Amputation & Deep infection & & \\
\hline 15 & Surgical excision and intramedullary rodding & Yes & Poor & $\begin{array}{l}\text { Deep infection } \\
\text { LLD of } 10 \mathrm{~cm}\end{array}$ & $\begin{array}{l}\mathrm{Cp} \\
\mathrm{Cs} \\
\mathrm{Ce} \\
\text { Csh } \\
\text { Total C } \\
\end{array}$ & $\begin{array}{l}\text { Pp } 1 \\
\text { Ps } 0 \\
\text { Pe } 2 \\
\text { Psh 0 } \\
\text { Total P } 3\end{array}$ \\
\hline 16 & Amputation & & Amputation & & & \\
\hline 17 & $\begin{array}{l}\text { Excision and intramedullary rodding twice at } 6 \text { years } \\
\text { interval }\end{array}$ & Yes & Fair & LLD of $3 \mathrm{~cm}$ & $\begin{array}{l}\text { Cp } 8 \\
\text { Cs } 8 \\
\text { Ce } 7 \\
\text { Csh } 4 \\
\text { Total C } 2\end{array}$ & $\begin{array}{l}\text { Pp } 11 \\
\text { Ps } 10 \\
\text { Pe } 9 \\
\text { Psh } 1 \\
\quad \text { Total P } 31\end{array}$ \\
\hline 18 & Excision and intramedullary rodding & Yes & Fair & LLD of $5 \mathrm{~cm}$ & $\begin{array}{l}\text { Cp } \\
\text { Cs } \\
\text { Ce } \\
\text { Csh } \\
\text { Total C }\end{array}$ & $\begin{array}{l}\text { Pp } 8 \\
\text { Ps } 2 \\
\text { Pe } 6 \\
\text { Psh } 0 \\
\text { Total P } 16\end{array}$ \\
\hline 19 & Surgical excision and intramedullary rodding & Yes & Poor & LLD $10 \mathrm{~cm}$ & $\begin{array}{l}\text { Cp } \\
\text { Cs } \\
\text { Ce } \\
\text { Csh } \\
\text { Total C }\end{array}$ & $\begin{array}{l}\text { Pp } 17 \\
\text { Ps } 10 \\
\text { Pe } 6 \\
\text { Psh 0 } \\
\text { Total P } 33 \\
\end{array}$ \\
\hline 20 & $\begin{array}{l}\text { Surgical excision and plating } \\
\text { Surgical excision and circular external fixation } \\
\text { Amputation }\end{array}$ & Yes & Amputation & & & \\
\hline
\end{tabular}

Key: C-Children, P-Parents, p-physical score, s-school score, e-emotional score and sh-shoe wearing score, LLD -Limb length discrepancy

in a well set orthopaedic centre of excellence. The indication for amputation was severe limb length discrepancy and deformity that could not resolve despite several reconstruction operations done

Treatment outcomes for patients managed by surgical excision and intramedullary rodding were as follows: good results $1 / 12(8.3 \%)$, fair results $6 / 12(50 \%)$, poor results $2 / 12$ (16.7\%) and amputation 3/12 (25\%). A study with Charnley-Williams method of intramedullary fixation being used for CPT treatment showed the following outcomes; eleven patients (48\%) ultimately had a grade-1 outcome (unequivocal union with full weight bearing function and maintenance of alignment requiring no additional surgical treatment); nine patients (39\%), a grade- 2 outcome (equivocal union with useful function, with the limb protected by a brace, and/ or valgus or sagittal bowing for which additional surgery was required or anticipated); and three patients (13.0\%), a grade-3 outcome (persistent nonunion or refracture, requiring full-time external support for pain and/or instability) 10 . In the aforementioned study, the mean follow-up duration was almost the same as this study in Malawi (7.1 vs 9), the result when compared appeared to be superior regarding large proportion of patients who had grade 1 and grade 2 outcomes, compared to good and fair results respectively in this study. These differences may be accounted for by the use of Charnley-Williams intramedullary rod compared to intramedullary rush rodding at $\mathrm{BCIH}$.
Another study which used intramedullary rodding for treatment of $21 \mathrm{CPT}$ patients, showed initial consolidation to have occurred in $18 / 21$ patients, refracture in $12 / 21$ patients from which $5 / 12$ fractures healed with closed treatment, $5 / 12$ fractures healed after an additional surgical procedure and 2 ultimately required amputation. They concluded 16/21 patients who got treated to have had a satisfactory longterm outcome, after a mean follow-up duration of 14.2 years (range 3 -20 years). ${ }^{11}$

A study done on treatment of CPT using intramedullary rodding after surgical excision showed that primary union was achieved in $6 / 7$ patients at a mean follow-up time of 4.5 months (range 4-6 months). Failure of obtaining the bone union was observed in the youngest patient after 13 months. However, the follow-up duration in this study is too short to make a tangible conclusion regarding the biological nature of CPT. ${ }^{12}$

Treatment outcomes for patients treated by surgical excision and circular external fixation, Ilizarov frames were as follows: $2 / 3$ poor results and $1 / 3$ amputation. A study done in Belgium among 12 patients with CPT, with a mean follow up of 24.5 years (range 6-39 years) used surgical excision and bone transport by Ilizarov frames with/without intramedullary nail augmentation. Union was achieved in 10/12 patients $(83 \%)$; however, half of these got refractured during follow-up. A second Ilizarov treatment again achieved successful union in three cases. In one patient tibia union could 
not be achieved and in another patient a below-knee amputation had to be done. ${ }^{8}$ In Norway, Ilizarov frames were used to treat 15 patients with CPT. A primary healing was achieved in $10 / 15$ patients (66\%), then $5 / 10$ patients refractured within 2 months of frame removal. However, all patients except one who were initially treated successfully with the Ilizarov frame refractured within 4 years after primary treatment. ${ }^{2}$ In general, treatment of CPT with Ilizarov frames is complex, time consuming, and resource demanding; the treatment outcomes vary and may not be cost effective in some settings.

In the current study, primary amputation was done in $4 / 20$ patients although, by the end of follow-up, amputation had been done in 9/20 (45\%) patients. Out of these 9 patients, prosthesis was accessible and functional in 5/9 patients (55.6\%). A study done in USA among 40 patients with CPT showed amputation to have been done in 14/40 patients (35\%). ${ }^{3}$ Another study which managed 7 patients using different treatment modalities got successful results in $1 / 7$. This particular study recommended that early primary amputation with an appropriate prosthesis should be considered..$^{13}$ The majority of these patients underwent several surgical procedures before amputation which led to uneconomical use of resources especially in resource scarce areas like Africa.

The recent study was done on patients with CPT, whereby they combined 4 modalities of treatment that is pseudarthrosis membrane excision, free periosteal grafting, bone grafting, intramedullary nailing on both tibia and fibula combined with Ilizarov fixation. In this study they reviewed 20 patients with minimum follow up of 2 years. The union was achieved after primary operation in all patients and ten refractures that underwent several secondary surgical procedures. No one patient underwent amputation. They used bisphosphonates as adjuvant therapy in three patients with refractures without subsequent refractures. ${ }^{14}$ The outcome in this study found better outcomes compared to the current study. This may be accounted for by resource availability and combination of 4 modalities of treatment in one patient.

Another study was conducted to review ten children with CPT. These children were treated with resection of pathologic bone, bone grafting, intramedullary rodding, compression with circular frame, simultaneous proximal tibia lengthening, and bone morphologic proteins. Thirteen operations were performed to achieve union. Four patients underwent simultaneous lengthening and four patients received recombinant human morphologic protein. Union of the pseudarthrosis was achieved in all cases with lengthening up to 5 $\mathrm{cm} .{ }^{15}$

In this current study, outcomes for non-amputated children were assessed using Oxford Foot and Ankle questionnaire scores (OxFAQ). The children had average physical score of 14.5, a school score of 9.6, an emotional score of 10.2 , a shoe status score of 2.7 and total children mean score of 37.4. The Parents average OxFAQ score was; physical score 10.6, school score 6.8, emotional score 8.1, shoe status score 1.8 and total parent mean score 28.5. These results were sim- ilar to another study which used different modalities to treat $\mathrm{CPT}$, including bracing, intramedullary nailing and circular frames. Among their 11 patients who completed follow-up, the Oxford Ankle Foot Questionnaire for children (Ox FAQ-C) mean score was 34 (range 12-50) and the Oxford Ankle Foot Questionnaire for parents (OxFAQ-P) mean score was 32 (range 13-50). ${ }^{9}$ However, OxFAQ primarily are not supposed to be reported by total value, every component like physical, school, emotional and shoe status scores should be reported separately. ${ }^{16}$ In this study, mean values have been added for research purposes to allow comparability. These mean values reflect moderate outcome results as added total values for a normal foot is 60 for Ox FAQ-C and 60 for OxFAQ-P.

\section{Complications}

In this study, complications occurred in 12/20 patients (60\%). Among these patients 11/12 (91.6\%) had limb length discrepancy ranging between $1-11 \mathrm{~cm}($ mean $6.6 \mathrm{~cm})$. Deep infection was found in $4 / 12$ patients $(33.3 \%)$. Pin tract infection was found in $1 / 12$ patients (8.3\%). Another study showed limb length discrepancy as the most common complication with a mean of $2.5 \mathrm{~cm}$ (range 0-7.5). ${ }^{9}$ Another study showed CPT patients treated with llizarov frames for bone transport in a patient who had residual LLD of $0 \mathrm{~mm}$ and one patient who sustained a residual shortening of $26.5 \mathrm{~cm}$ at the end of growth. ${ }^{8}$ All these findings reflect limb length discrepancy as the main complication challenge on CPT treatment.

\section{Preferred treatment modality for CPT}

The CPT is such a complex childhood disorder which renders challenges on management to achieve a good outcome. The recent published research studies have advocated for the approach towards managing CPT that could achieve union in these patients. The risk of refracture is still existing in this approach which is summarized in Figure 1. ${ }^{14,15}$

\section{Limitations}

The majority of these patients got treated 10 years ago. That was the time when mobile network was still in establishment process in Malawi urban areas, so few patients had phone numbers or reliable contacts. Those who came from the rural areas had no reliable contacts at all. This limited our capacity to access those patients for the review. This accounted for much of loss to follow up in this study despite walking in all villages that are shown to belong to these patients in our database.

\section{Conclusions}

Congenital pseudarthrosis of the tibia is a complex congenital disorder. Multiple modalities of treatment have been designed for this disorder, still no one treatment modality reassures good outcome. This condition affects mostly males, and the majority are classified as Crawford CPT stage 4 . The majority of patients after being treated by more than one surgery may end up with amputation or poor outcome. The complications associated with congenital pseudarthrosis of tibia include limb length discrepancy, deep infection and pin tract infection. 
Congenital pseudarthrosis of the tibia Treatment

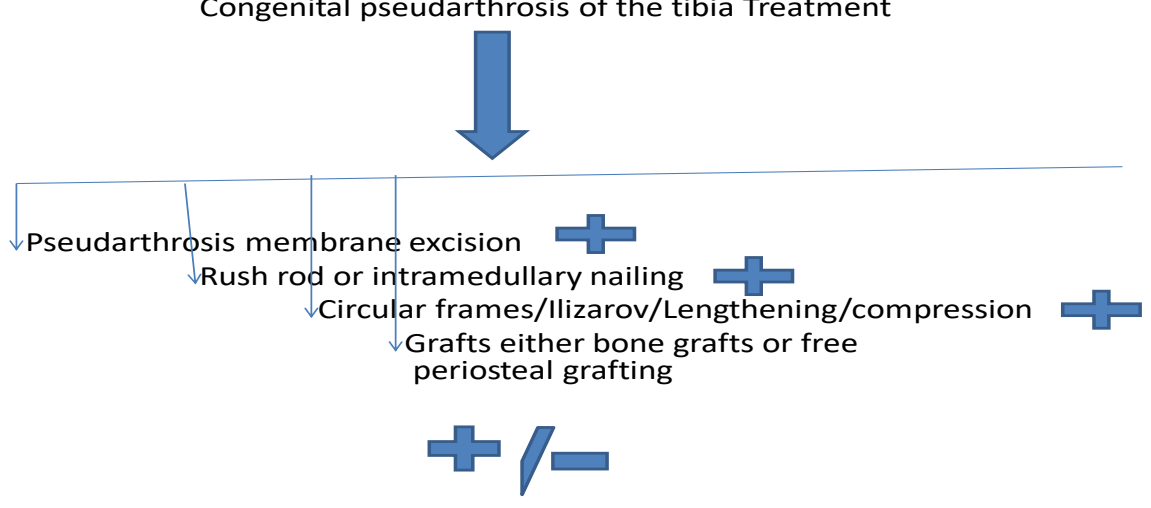

Bisphosphonates +/- Bone morphologic proteins

Figure 1: Preferred treatment pathway for congenital pseudarthrosis of the tibia
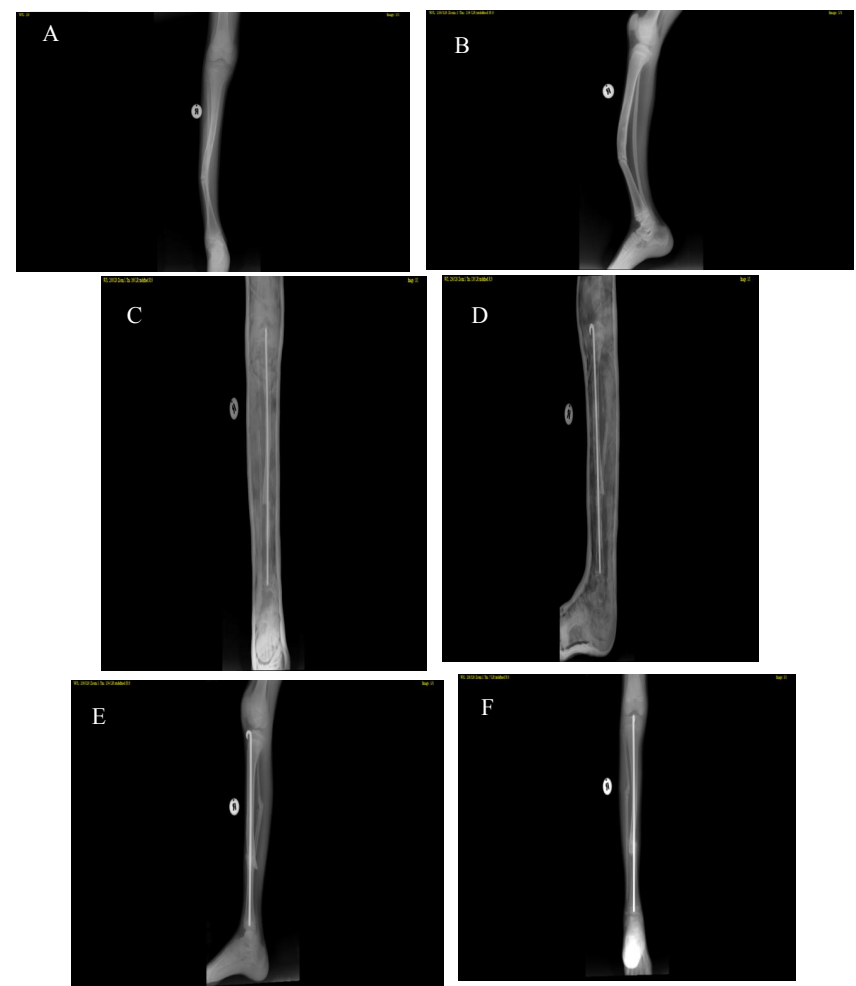

Figure 2: Tibia/fibula x-ray images of a girl with CPT Crawford stage 4. (A) and (B) Preoperative; (C) 1 day after pseudarthrosis membrane excision, fracture clearing, reduction and rush rodding, with cast AP view; (D) 1 day after surgery, lateral view; (E) 3 months after surgery (still no adequate callus formation), AP view; (F) 3 months after surgery (still no adequate callus formation), lateral view

\section{Recommendations}

We recommend a thorough clinical judgment from the beginning of CPT treatment, to consider multiple factors during decision making and to come up with a clear plan for reconstruction and/or amputation. In resource-limited settings like in many countries in Africa, if prosthesis services are available, primary amputation may be a better option which is also cost effective. We also recommend judicious
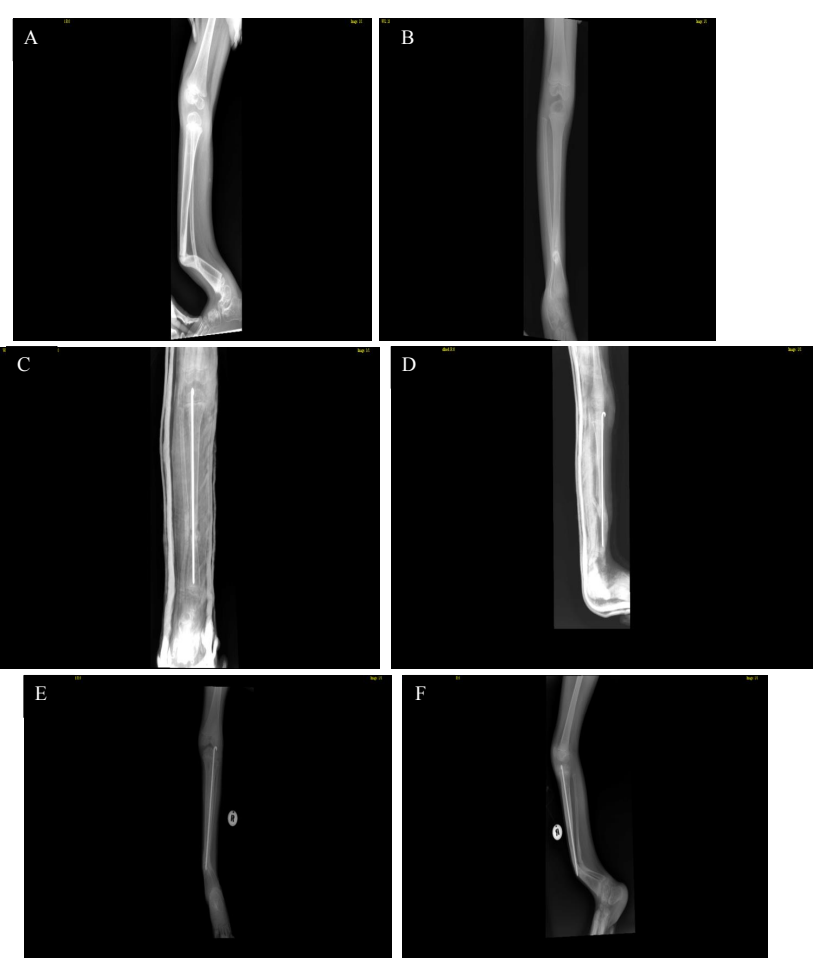

Figure 3: Tibia/fibula x-ray images of a girl with CPT Crawford stage 4. (A) and (B) Preoperative; (C) 1 day after pseudarthrosis membrane excision, fracture clearing, reduction and rush rodding, with cast AP view; (D) 1 day after surgery, refractured 5 months after surgery, lateral view; she ended up undergoing amputation

counseling to be done for all patients from the beginning, with detailed explanations on advantages and disadvantages following either reconstruction and/or primary amputation. 

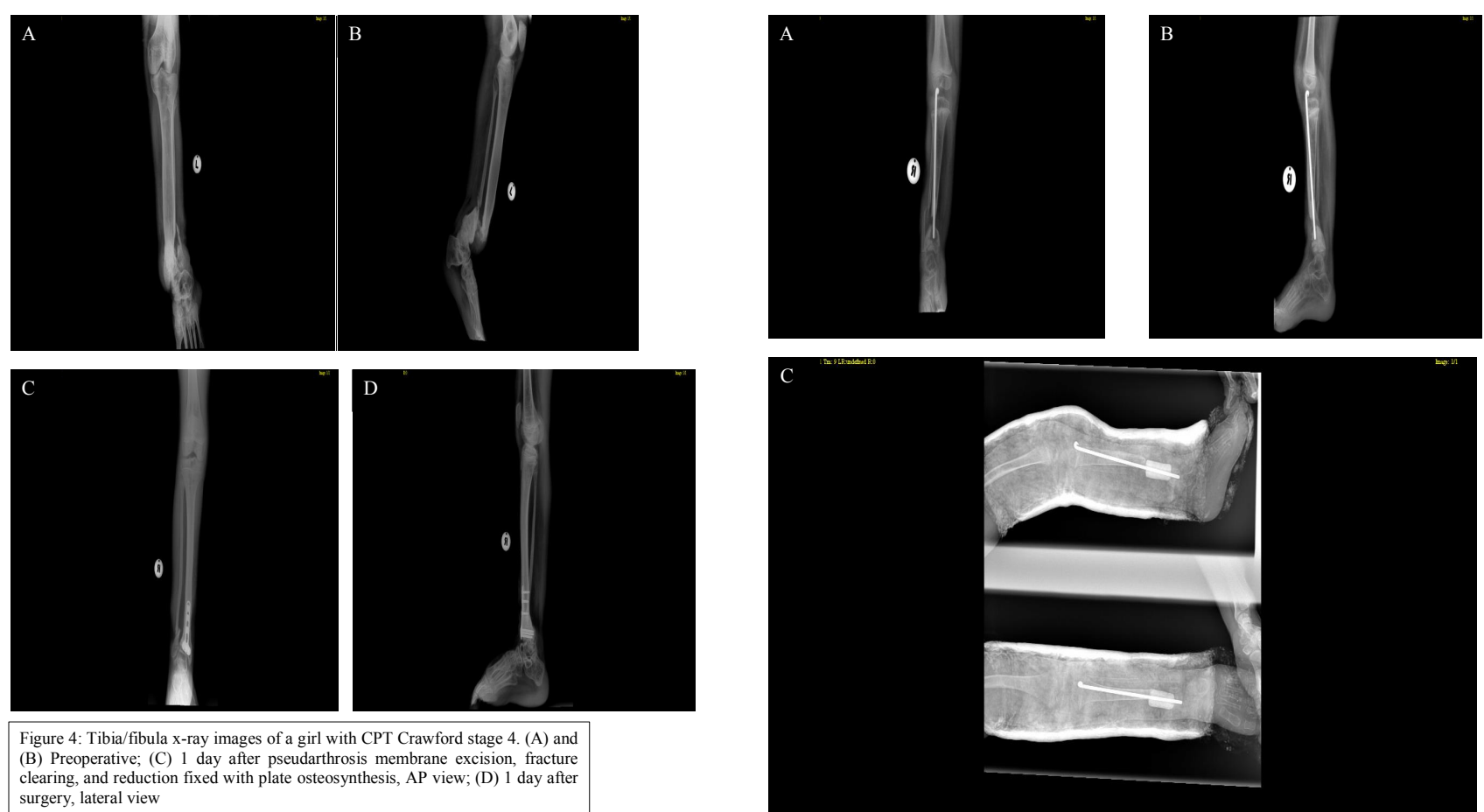

Craw ford stage 4. (A) and (B) Preoperative; (C) 1 day after pseudarthrosis membrane excision, fracture clearing, and reduction
surgery, lateral view

Figure 5: Tibia/fibula x-ray images of a girl with CPT Crawford stage 4. (A) Postoperative after pseudarthrosis membrane excision, fracture clearing, reduction and rush rodding, ended up with nonunion, AP view; (B) postoperative, still with non-union, lateral view. (C) After non-union was observed, revision surgery was carried out, including the addition of bone cement (methyl methacrylate) (top is lateral view, bottom is AP view).
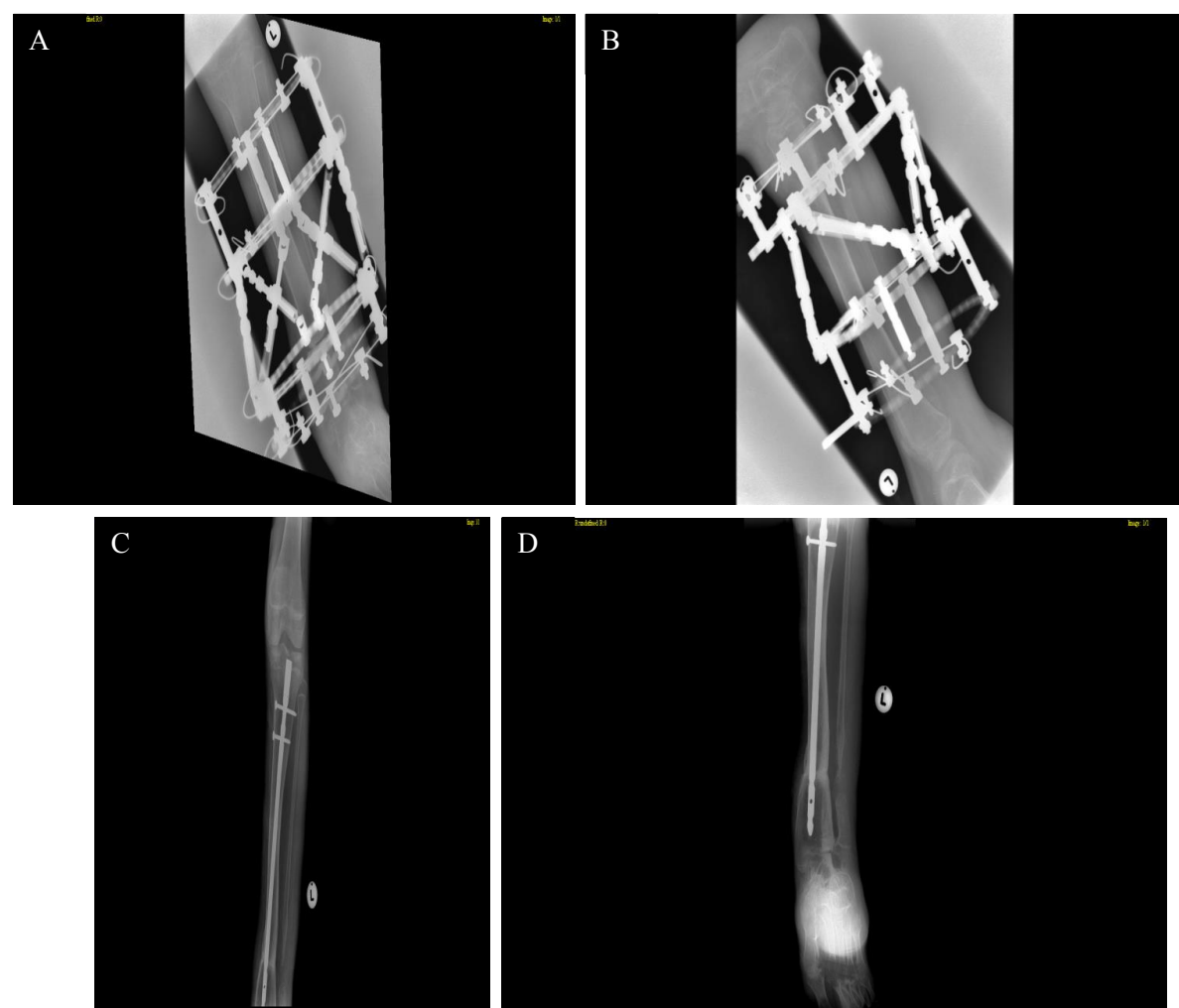

Figure 6: Postoperative tibia/fibula $\mathrm{x}$-ray images of a boy with CPT Crawford stage 4 . He was first treated with rush rod that failed, then (A, lateral view; and B, AP view) a circular frame (Taylor Spatial Frame) was used to enable fracture compression and healing. (C, AP view) Then he was re-operated with locking intramedullary nailing, and (D, lateral view) callus formation was observed. 


\section{Competing interests}

All authors declare that they have no competing interests related to this work.

\section{References}

1. Andersen KS. Congenital angulation of the lower leg and congenital pseudarthrosis of the tibia in Denmark. Acta orthopaedica Scandinavica. 1972;43(6):539.

2. Horn J, Steen H, Terjesen T. Epidemiology and treatment outcome of congenital pseudarthrosis of the tibia. Journal of children's orthopaedics. 2013;7(2):157-66

3. Morrissy RT, Riseborough E, Hall J. Congenital pseudarthrosis of the tibia. Journal of Bone \& Joint Surgery, British Volume. 1981;63(3):367-75.

4. Andersen KS. Congenital pseudarthrosis of the tibia and neurofibromatosis. Acta Orthopaedica. 1976;47(1):108-11.

5. Morris C, Doll H, Wainwright A, Theologis T, Fitzpatrick R. The Oxford ankle foot questionnaire for children scaling, reliability and validity. Journal of Bone \& Joint Surgery, British Volume. 2008;90(11):1451-6.

6. Martinkevich P, Møller-Madsen B, Gottliebsen M, Pedersen LK, Rahbek O. Validation of the translated Oxford ankle foot questionnaire in 82 Danish children aged between five and 16 years. Bone \& Joint Journal. 2015;97(3):420-6.

7. Crawford Jr A, Bagamery N. Osseous manifestations of neurofibromatosis in childhood. Journal of Pediatric Orthopaedics. 1986;6(1):72-88.

8. Vanderstappen J, Lammens J, Berger P, Laumen A. Ilizarov bone transport as a treatment of congenital pseudarthrosis of the tibia: a long-term follow-up study. Journal of children's orthopaedics. 2015;9(4):319-24.

9. Nicolaou N, Ghassemi A, Hill R. Congenital pseudarthrosis of the tibia: the results of an evolving protocol of management. Journal of children's orthopaedics. 2013;7(4):269-76.

10. Johnston II CE. Congenital pseudarthrosis of the tibia: results of technical variations in the Charnley-Williams procedure. Journal of Bone and Joint Surgery. 2002;84(10):1799.

11. Dobbs MB, Rich MM, Gordon JE, Szymanski DA, Schoenecker PL. Use of an intramedullary rod for treatment of congenital pseudarthrosis of the tibia. The Journal of Bone \& Joint Surgery. 2004;86(6):1186-97.

12. Shadi M, Koczewski P. Complex treatment of congenital pseudarthrosis of the tibia with periosteal grafting and intramedullary fixation. Postępy Nauk Medycznych. 2012.

13. Lehman WB, Atar D, Feldman DS, Gordon JC, Grant AD. Congenital pseudoarthrosis of the tibia. Journal of Pediatric Orthopaedics B. 2000;9(2):103-7.

14. Thabet AM, Paley D, Kocaoglu M, Eralp L, Herzenberg JE, Ergin ON. Periosteal grafting for congenital pseudarthrosis of the tibia: a preliminary report. Clinical orthopaedics and related research. 2008 Dec;466(12):2981-94. PubMed PMID: 18953621. Pubmed Central PMCID: 2628232 .

15. Shabtai L EE, Wientroub S, Segev E. Congenital tibial pseudarthrosis, changes in treatment protocol. Journal of Pediatric Orthopaedics B. 2015 Sept;24(5):444-9.

16. Morris C, Doll H, Davies N, Wainwright A, Theologis T, Willett K, et al. The Oxford Ankle Foot Questionnaire for children: responsiveness and longitudinal validity. Quality of Life Research. 2009;18(10):1367-76. 